DOI: $10.20396 /$ lil.v23i45.8659383

\title{
DESIGNAÇÕES DE TEXTO NA EDUCAÇÃO BÁSICA
}

\section{Wagner Ernesto Jonas Franco* UNIVÁS}

Resumo: Este artigo se inscreve na área da Semântica do Acontecimento. $O$ objetivo é analisar as designações da palavra texto em entrevistas com professores das diversas disciplinas do ensino médio de uma escola em Pouso Alegre, MG. O procedimento de análise considerou como a palavra texto articulava-se e se reescriturava em enunciados que integravam os respectivos textos (entrevistas). Com isso, percebemos que o funcionamento político da enunciação produz a instabilidade da designação da palavra texto. Nas entrevistas com os professores, separamos as disciplinas em três grupos de acordo com os sentidos comuns à palavra texto. Em geral, as disciplinas visam a ensinar um conteúdo disciplinar descarnado de sua história, o que acaba por colocar o ensino do texto como um aspecto secundário na Escola.

Palavras-chave: Semântica, Texto, Professor.

Abstract: This article is in the Semantics of the Events area. The objective is to analyze the designations of the word text in interviews with teachers from the various high school disciplines of a school in Pouso Alegre, MG. The analysis procedure considered how the word text was articulated and rewritten in statements that integrated the respective texts (interviews). With this, we perceive that the political functioning of the enunciation produces the instability of the designation of the word text. In the interviews with the teachers, we separate the disciplines into three groups according to the common meanings to the word text. In general, the disciplines aim to teach a disciplined content, which ends up putting the teaching of the text as a secondary aspect in the School.

Keywords: Semantics, Text, Teacher. 


\section{Introdução}

Este trabalho objetiva compreender a designação ${ }^{1}$ de texto em entrevistas concedidas por professores de diversas disciplinas do ensino médio, período noturno, de uma escola pública municipal em Pouso Alegre, MG. Especificamente, analisamos entrevistas orais feitas pelo autor do artigo com os professores da referida escola. As entrevistas, gravadas e transcritas, foram realizadas no ano de 2016. Quatorze professores de doze disciplinas foram entrevistados ${ }^{2}$.

Para lançar luz sobre nossas questões, utilizaremos a fundamentação teórico-metodológica da Semântica do Acontecimento, assim pensada por Guimarães (2001, 2002, 2011 entre outros), Zoppi-Fontana (2012), e outros. Essa é uma disciplina materialista (não referencialista) de estudo da linguagem, que toma como unidade de análise o enunciado que integra texto. Mobilizamos também, ressalvadas as diferenças entre as duas disciplinas, alguns conceitos da Análise de Discurso Pecheuxtiana, principalmente, o que esta disciplina tem a dizer a respeito da relação entre texto e autoria.

O diferencial desta pesquisa está em colocar em discussão como os professores das várias disciplinas do ensino médio (e não apenas a disciplina de Língua Portuguesa) compreendem língua e texto, pois, tradicionalmente, a tarefa de ensinar a compreender os diferentes textos é atribuída ao professor das disciplinas de línguas. Mas, como as outras disciplinas são também trabalhadas a partir da língua, concordamos com Gallo (1994, p. 24) quando diz: "o conteúdo da disciplina de língua materna identifica-se com os conteúdos de todas as outras disciplinas". Por essa razão, a compreensão de língua(gem) e de texto dos professores das várias disciplinas do currículo escolar exerce papel crucial para o ensino formal do aluno.

\section{Fundamentação teórica}

O que é texto para a Semântica do Acontecimento? Como essa disciplina linguística pensa a textualidade? Responder a estas questões é pensar antes de tudo no conceito de enunciação. Para essa disciplina da Linguística, o sentido se dá "a partir do funcionamento da linguagem no acontecimento da enunciação" (GUIMARÃES, 2010, p. 11). Isto é, a enunciação é tomada como um acontecimento da linguagem que produz o sentido. Este primeiro conceito, então, - o de acontecimento - é fundamental. Para Guimarães (2011): 
O acontecimento é o que faz diferença na sua própria ordem. E o que especifica este acontecimento é a temporalidade que ele constitui. Assim, um acontecimento não é considerado em virtude de estar num certo momento do tempo, antes de um outro acontecimento também no tempo. Não é este aspecto que considero como especificador de um acontecimento. $\mathrm{O}$ que especifica um acontecimento é a temporalidade que ele constitui: um passado, um presente e um futuro. Ou seja, um acontecimento é distinto de outro acontecimento porque ele recorta um passado de sentidos que convive com o presente da formulação do Locutor e assim traz uma projeção de futuro de sentidos que não significariam não fosse $\mathrm{o}$ acontecimento em questão (GUIMARÃES, 2011, p. 15).

É, pois, o acontecimento que produz a significação. Ele não é um fato empírico que se dá em um tempo anterior e exterior à linguagem ou em um tempo estabelecido pelo sujeito. $\mathrm{O}$ acontecimento constitui sua temporalidade, não estando em um presente de um antes e de um depois no tempo, mas há um tempo que significa porque o acontecimento é perpassado pelo interdiscurso, que é o "espaço de memória no acontecimento" (GUIMARÃES, 1995, p. 65). Portanto, o acontecimento pode estar conectado a outros que já existiram e pode projetar acontecimentos futuros.

$\mathrm{O}$ acontecimento do funcionamento da língua se dá no espaço de enunciação, que é o espaço de relação de línguas e falantes. Não é a língua somente que produz a significação, mas ela na relação com o falante. Os espaços de enunciação são espaços políticos de funcionamento linguístico. Ou seja, são espaços de conflitos e disputas pelas palavras e pelas línguas, espaços de "conflito entre uma divisão normativa e desigual do real e uma divisão pela qual os desiguais afirmam seu pertencimento" (GUIMARÃES, 2002, p. 16). O político é parte do funcionamento das línguas. Como diz Zoppi Fontana (2012, p. 7): "Por ser necessariamente atravessada pelo 
político, a língua é marcada por uma divisão, pela qual os falantes se identificam".

O falante, por sua vez, não é o indivíduo físico que realiza o ato de falar, mas uma "figura política constituída pelo espaço de enunciação" (GUIMARÃES, 2002, p. 18). O funcionamento da língua, no espaço de enunciação, agencia o falante a falar, produzindo o acontecimento da enunciação. Falar não é uma prática individual e subjetiva, mas uma prática política. Enuncia-se em um espaço de enunciação que é determinado historicamente com relação sempre dividida entre línguas.

Segundo Guimarães (2011), no acontecimento de enunciação, o falante é tomado como Locutor (L), que é o lugar que se representa no próprio dizer como sua fonte. Mas, a figura do Locutor não é una e homogênea, há uma disparidade constitutiva entre o Locutor e os lugares sociais autorizados a falar que afetam o Locutor, "para o Locutor se representar como origem do que se enuncia, é preciso que ele seja agenciado por um lugar social de locutor" (GUIMARÃES, 2011, p. 23). Esse lugar social, o autor denomina de locutor- $x^{3}$, onde $\mathrm{x}$ é a variável que representa esse lugar social (professor, presidente, governador etc.).

O Locutor e o locutor-x são figuras enunciativas fundamentais para a compreensão da cena enunciativa, que são "modos específicos de acesso à palavra dadas as relações entre figuras de enunciação e as formas linguísticas" (GUIMARÃES, 2002, p. 23). É na cena enunciativa que se percebe o funcionamento do acontecimento. Compreender a cena enunciativa é compreender o próprio modo de constituição dos lugares do Locutor e do locutor-x pelo funcionamento da língua.

Segundo Schereiber da Silva et al (2011), a cena enunciativa mobiliza modos de construção dos lugares de dizer. Lugares que se referem a um "aquele que fala" e "aquele para quem se fala". Na cena enunciativa, vislumbra-se a disparidade do sujeito da enunciação: um Locutor (com L maiúsculo) que se representa no próprio dizer como sua fonte, especificando o tempo do dizer como contemporâneo de si. O Locutor não é um lugar abstrato, ao se conceber como origem de si, o Locutor obriga-se a uma divisão, pois está afetado por lugares sociais que o autorizam a falar. O locutor-x é esse lugar social. 
Na composição da cena enunciativa, ainda se deve considerar os lugares de dizer, ou seja, os enunciadores, que são figuras que "representam no acontecimento enunciativo (e, portanto, nos enunciados nele produzidos) diversos modos de apagamento do lugar social do locutor" (ZOPPI-FONTANA, 2012, p. 9). Em outras palavras, o lugar de dizer representa o apagamento do político (no sentido de disputa pelas palavras) no acontecimento enunciativo. Os enunciadores podem ser representados a partir de um lugar de dizer individual, coletivo, genérico e universal. Os enunciadores caracterizam-se pelos seguintes aspectos: no enunciador individual, um locutor apresenta-se como um indivíduo específico que diz para um indivíduo também específico. No enunciador coletivo, diz-se a partir de um lugar corporativo, de um conjunto que o dizer apresenta como um todo específico. O enunciador genérico é próprio de provérbios e ditados populares. No enunciador universal, há um sentido de universalidade, um dizer que é voltado para todos.

A cena enunciativa não é unívoca. Tem-se para ela a seguinte configuração: um Locutor com seu correlato, o Alocutário. Um locutor-x com seu correlato, o alocutário-x. E o enunciador correlaciona-se com seu dizer. De forma esquemática, na composição da cena enunciativa, temos:

Locutor (L) ---------------------------------------- Alocutário (Al)

Locutor-x ---------------------------------------- alocutário-x (al-x)

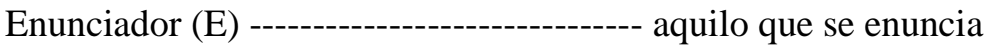

As figuras da enunciação são importantes para compreender e interpretar textos. Esses e outros conceitos mostram os procedimentos que utilizaremos para ler os textos de nossas análises. Para o semanticista, o acontecimento da leitura do texto se dá sempre de forma díspar ao acontecimento da enunciação do texto. Falemos um pouco mais a esse respeito.

Pode-se perguntar de forma geral: Qual é o lugar do leitor de texto? De forma específica, falamos do lugar de semanticistas, mas os procedimentos de análise são profícuos para se pensar aspectos da leitura de forma geral. O lugar do leitor é o correlato do lugar do autor. Mas, este enquanto engajado no lugar social de locutor-x com o todo do texto. Considerar o todo do texto na relação com um autor que 
é um lugar social de locutor-x (e não com o Locutor garantidor da unicidade do texto) tem como consequência a caracterização do texto como múltiplo.

Analisar um texto é levar em conta a disparidade entre o Locutor (aquele que se apresenta como origem do dizer, garantidor de unicidade) e o lugar social de locutor (lugar do múltiplo). É considerar a não linearidade e não logicidade do texto. Ler, principalmente da posição de analista, é considerar o texto consigo mesmo e com aquilo que lhe é exterior. É saber que os sentidos não estão todos no texto. A leitura do texto não se dá na relação:

\section{Locutor ----------------- Alocutário}

E toda uma univocidade aí envolvida. "Ser leitor é estar num lugar social, portanto histórico, no intercurso enunciativo" (GUIMARÃES, 2013, p. 195).

Mas não é só isso. A leitura de um texto pode se dar de diferentes lugares. O lugar "previsto" pelo texto é apenas parte de seus sentidos. Pode-se ler um texto da posição de historiador, linguista, filósofo, entre outros. Necessário ressaltar que a relação de leitor não se dá pela vontade individual e não é uma relação pragmática, é uma relação constituída na cena enunciativa. Portanto: "não se pode analisar um texto sem levar em conta seu próprio modo de enunciação e aquilo que ele estabelece pelo funcionamento de suas formas de linguagem, mas o lugar de leitor não é o lugar projetado no texto pelo autor" (GUIMARÃES, 2013, p. 197). Mas, qual é a definição de texto e textualidade para A Semântica do Acontecimento? Falemos sobre esses conceitos a seguir.

\section{Texto, Textualidade e Semântica}

Os textos são unidades complexas de significação e estão presentes praticamente em toda a vida do homem. São diversos os textos presentes na sociedade e aqueles com os quais entramos em contato incidem diretamente na formação de nossa identidade. Por estar tão presente na sociedade, parece ser do senso comum que todos saibam o que é texto, mas, a formulação de uma definição para essa unidade de sentido é necessária segundo o campo de estudo em que se trabalhe. No caso deste trabalho, o campo da semântica. 
Para a Semântica do Acontecimento, o texto importa porque significa e esta disciplina interessa-se pelo texto não somente para dizer como algo faz texto, mas estabelecer procedimentos para analisar diversos textos, literários ou não. De acordo com Guimarães:

O texto é unidade de significação. Não se trata de dizer que o texto tem unidade, mas que ele é uma unidade, assim como a palavra é uma unidade, o enunciado é uma unidade, etc. E esteve e está sempre presente para mim que a questão do texto é uma questão semântica (GUIMARÃES, 2011, p. 9).

Melhor especificando, o texto é "uma unidade de sentido que integra enunciados no acontecimento da enunciação" (GUIMARÃES, 2011, p. 19). A unidade produz sentido e é isso que a faz texto. O texto integra enunciados ou, dito de outra forma, o texto é integrado por enunciados. Mas, é preciso ressaltar que essa unidade de sentido não significa que o texto seja uno, que o sentido seja unívoco. A unidade está no sentido de ser algo finito e integrar outras unidades que são os enunciados. Estes significam justamente porque estão nesta relação de integração com o texto.

A caracterização acima de texto vai contra uma ideia corrente, principalmente no meio escolar, de que texto é conjunto de enunciados (ou palavras). Dizer que um texto integra enunciados não é dizer que estes existem previamente e, no texto, reúnem-se com similaridade de sentidos. Os enunciados significam de certa forma em certos textos e, em outros, podem significar diferentemente. Isso também se relaciona com o fato de que os textos possuem suas "histórias de leituras" (ORLANDI, 1988). Histórias que se constituem em memória e significam no texto a ler. Distanciamo-nos, assim, mais uma vez, de uma compreensão situacional-empírica do texto. A integração do enunciado ao texto é constituída pelo acontecimento da enunciação.

No acontecimento enunciativo, a posição-autor que aí se configura recorta o interdiscurso como algo que começa e termina. O acontecimento do texto apresenta-se como singular por um efeito, uma ilusão necessária ao dizer. $\mathrm{O}$ autor toma como suas as palavras que 
são por direito do interdiscurso: "Esta é a operação enunciativa fundamental para a textualidade: construir como unidade o que é disperso" (GUIMARÃES, 1995, p. 67).

Guimarães considera dois funcionamentos próprios à textualidade: a coesão e a consistência:

A coesão diz respeito às relações que reenviam a interpretação de uma forma à de outra, numa sequência do texto. A consistência diz respeito às relações que reenviam a interpretação de uma forma ao acontecimento enunciativo (GUIMARÃES, 1995, p. 67).

O autor não considera aqui a noção de coerência - mais comum à Linguística Textual - porque isso seria relacionar o acontecimento enunciativo com algo cognitivo e, assim, descartaria seu aspecto histórico.

Um conceito importante para a questão da textualidade é a reescritura ou reescrituração. É o procedimento pelo qual a enunciação de um texto rediz insistentemente o que já foi dito. É uma volta ao dito para continuar dizendo no batimento entre paráfrase e polissemia ${ }^{4}$. A reescritura faz com que algo dito signifique como diferente de si. Não é um procedimento que se dá apenas pela linearidade do texto, mas também pode ser construído de forma transversal. Nas palavras de Guimarães (2002):

A reescrituração é uma operação que significa, na temporalidade do acontecimento, o seu presente. A reescrituração é a pontuação constante de uma duração temporal daquilo que ocorre. $\mathrm{E}$ ao reescriturar, ao fazer interpretar algo como diferente de si, este procedimento atribui (predica) algo ao reescriturado. E o que ele atribui? Aquilo que a própria reescrituração recorta como passado, como memorável. [...] E esse movimento de predicação na duração do presente pelo memorável significa porque projeta um futuro, o tempo da interpretação no depois do acontecimento no qual o reescriturado é refeito pelo reescriturante (GUIMARÃES, 2002, p. 28). 
Ao predicar algo ao reescriturado, a reescrituração coloca em funcionamento uma operação de predicação. É “uma operação pela qual, no fio do dizer, uma expressão se reporta a outra, pelos mais variados procedimentos" (GUIMARÃES, 2007, p. 84). A reescrituração pode se dar de diversos modos. De forma suscinta, pode-se caracterizar alguns desses modos como:

Repetição: quando um termo ou expressão ditos anteriormente são retomados igualmente de forma completa ou reduzida.

Substituição: um termo ou expressão são retomados por outro termo ou expressão, mas com ele mantém uma certa relação de sinonímia.

Elipse: quando um termo ou expressão são omitidos na frase.

Expansão: um termo ou expressão são retomados de maneira ampliada ou expandida, os termos ou expressões são ditos de uma forma mais explicativa.

Condensação: um termo ou expressão (como tudo, caso) condensa uma narrativa ou uma série de termos enunciadas anteriormente.

Definição: quando a enunciação do texto define termos ou expressões ditos anteriormente. Ou seja, a enunciação diz o que o termo é.

A reescrituração também pode se dar por modos diferentes: por especificação, por desenvolvimento, por generalização, por totalização e por enumeração. Importante ressaltar que esses diferentes modos não são exclusivos. Um modo de se reescriturar pode acontecer juntamente com outros. Por exemplo, uma substituição pode ser por especificação e uma expansão pode se dar por enumeração ou desenvolvimento. A reescritura é o próprio modo de se construir o sentido de um termo ou expressão na enunciação, na medida em que uma retomada faz significar algo que não estava significado. A partir dos conceitos postos acima, passemos às análises das entrevistas.

\section{A cena enunciativa para as entrevistas com professores}

Para este corpus de pesquisa, a cena agencia um alocutor-professor a falar sobre sua disciplina para um alocutário-entrevistadorpesquisador-professor, e há uma relação alocutor-cientista agenciado a questionar o alocutário-professor no espaço escolar, um "espaço de relações de sentido que investem nos sujeitos formas e gestos de 
interpretação muito específicos que conformam suas relações sociais" (PFEIFFER, 2011, p. 235). Ainda um espaço conflituoso de falantes e línguas, um espaço que, como diz Lagazzy-Rodrigues (2003):

[...] faz parte desse conjunto heteróclito que compõe o sistema lógico estabilizado da sociedade moderna, configurando-se como um "espaço de necessidade equívoca", para usar as palavras de Pêcheux (...). [Um espaço que] expõe nossas necessidades equívocas. Da parte dos docentes: conseguir ensinar e preparar bem os alunos para o futuro, ter boa didática, transformar a sociedade, ser querido pelos alunos... Da parte dos alunos: aprender, e para isso entender tudo e acabar com as dúvidas, preparar-se para o futuro, chegar ao saber... Enfim, cada um tem a necessidade de "ser feliz", de se completar, um pouco a cada aula, num movimento progressivo e constante (LAGAZZYRODRIGUES, 2003, p. 67-68).

Nesta cena, há um jogo de imagens (PÊCHEUX, 1969) que agencia o alocutor-professor a falar considerando a imagem que faz de seu alocutário-entrevistador, e como alocutário indireto, tem-se a figura do aluno. Analisamos as entrevistas individualmente, considerando que os enunciados são produtos da relação do sujeito com sua formação pedagógica, com sua história e sua língua. Os enunciados são produzidos num espaço conflituoso de falantes e de língua que se dividem politicamente.

Nas análises que se seguem, dividimos as disciplinas em três grupos de acordo com as designações de texto apresentadas. Essa divisão nos traz conclusões interessantes. Uma delas é que a classificação por área de "exatas" ou "humanas" não determina o sentido dos textos. Vejamos.

\section{O texto como meio de transmitir uma informação}

As disciplinas reunidas neste grupo são: Língua Portuguesa, Literatura, História, Física 1, Biologia e Sociologia. Veremos que, para essas disciplinas, o texto é um meio de transmitir uma 
informação, uma mensagem, um conteúdo. Importa pouco saber sobre o texto, este é subterfúgio para que determinado conteúdo seja ensinado.

Iniciemos com as disciplinas de Língua Portuguesa e Literatura. As análises que se seguem partem de recortes que compõem as respostas à pergunta: Como você define o que é um texto para sua disciplina? Mas não unicamente a ela. Traremos outros recortes da entrevista conforme nosso objetivo. Lembramos que a mesma professora ministra as duas disciplinas. Repetiremos a pergunta ao longo dos recortes para melhor compreensão. Vamos ao primeiro recorte ${ }^{5}$ :

R1: (1) Olha, além das tipologias, né, já pré-definidas, como narrativo, dissertativo, é..., descritivo, artigo de opinião, essas partes, assim, mais teóricas, (2) eu acho que é tudo aquilo que transmite mensagem, né, que tenha uma coerência, que tenha uma coesão, que possa expressar as ideias nele contidas, que ... seja eles literários ou não, desde que transmita uma informação, e, dessa informação, possa gerar argumentos para que o aluno possa se defender.

A primeira parte (1) do recorte é dita a partir de um enunciador genérico que já considera estabelecidas as tipologias textuais na escola. As tipologias textuais como a narração, a dissertação, a descrição, e o alocutor-professor inclui o artigo de opinião, são prédefinidas, ou seja, considera-se o texto a partir dessa definição préestabelecida. Pré-definidas por quem? Esse dizer insere-se na memória de sentidos da escola como um pré-construído sempre presente. Ao enunciar pré-definido, o alocutor-professor temporaliza um presente de sentidos para essa memória já estabelecida na escola e projeta o sentido de que sempre se deve trabalhar com essas tipologias textuais. $\mathrm{O}$ enunciador-genérico generaliza a fala e torna esse aspecto teórico do tratamento do texto como o único possível. A enunciação de pré-definidos funciona como um argumento que autoriza o alocutor-professor a trabalhar com as tipologias textuais.

As tipologias textuais citadas no recorte são um conceito teórico elaborado por Egon Werlich, em 1975, em sua obra Typologye der Texte e bastante trabalhado e retrabalhado na Linguística textual. Esse 
conceito está presente em livros didáticos de Língua Portuguesa da década de 1980 em diante. Os Parâmetros Curriculares Nacionais do Ensino Médio, especificamente, não citam classificações de textos como os das tipologias textuais.

Na segunda parte do recorte, o lugar de fala é o do enunciador individual, marcado pelo eu acho. Texto aparece primeiramente em uma reescrituração por elipse em: [texto] é tudo aquilo que transmite mensagem. O pronome indefinido tudo predica sentidos para texto. Tudo recorta como memorável o aspecto verbal e o não verbal que caracterizam um texto. O pronome tudo é uma palavra equívoca, nela cabem muitos sentidos.

Então, a enunciação traz uma enumeração de definições de texto que podem ser parafraseadas como se segue:

1') O texto transmite mensagens, tem coerência, coesão, expressa ideias, transmite informações, gera argumentos que podem ser utilizados como defesa.

O professor da disciplina prioriza o aspecto informacional do texto e como objeto que se encerra em si mesmo, sem um sujeito que o produz. Os elementos principais da textualidade continuam sendo a coesão e a coerência.

Consideremos agora a seguinte paráfrase:

\section{1',) O texto gera argumentos para que o aluno se defenda.}

Essa paráfrase coloca em relevo que o texto possui um aspecto formador para o aluno. Que lugar projeta-se para o aluno leitor de textos nesse enunciado? O aluno é um sujeito vir a ser, é um sujeito embrionário (PFEIFFER, 2000). Na progressão da enunciação há um sentido de mensagem, ideia e informação que se projeta sobre argumentos. Mensagem, ideia e informação são conteúdos do texto que, ao serem apropriados pelo aluno em seu processo de formação, transformam-se em argumentos.

Vejamos como o texto na relação com a informação é posta pelos dois alocutores-professores da disciplina de Biologia. Iniciemos com o recorte do alocutor-professor de Biologia 1: 
$\mathrm{R} 2$ : Como você define o que é um texto para sua disciplina? $\mathrm{O}$ texto...é ... seria as informações necessárias pra se formar uma ideia, então, o texto seria um meio de se passar uma ideia, de transmitir essa ideia.

O recorte 2 é dito a partir de um enunciador individual, pois é modalizado pela forma verbal seria, que indica uma dúvida. O alocutor-professor coloca em relevo o caráter informacional do texto e também formador de uma ideia. $\mathrm{O}$ texto é definido enumerativamente como meio de se passar uma ideia e [meio de] transmitir uma ideia. A relação que se coloca para o leitor do texto é unilateral, o leitor apreende as informações ou ideias do texto passivamente. Essa relação unilateral fecha o texto em si mesmo.

Vejamos um próximo recorte deste alocutor-professor de Biologia 1 que é a resposta à pergunta 2 , para que você utiliza os textos em sala de aula?

R3: (1) O texto é muito engessado e não propicia a reflexão, ou seja, não f... atualmente, o que se lê em Biologia não é algo reflexivo e acaba fomentando mais respostas prontas, então, (2) eu vejo que poderia melhorar, mas é fundamental, justamente para articular esta capacidade analítica do... do aluno.

A parte (1) do recorte3 é enunciada a partir de um enunciador universal, pois o sentido é de uma verdade para todos. Enunciar que $o$ texto é muito engessado recorta como memorável um sentido de texto como conjunto de informações e sua leitura se daria unilateralmente apenas para a apreensão das ideias do autor pelo leitor. O texto é muito engessado, é um enunciado que pode ser parafraseado por:

3') O texto possui um sentido único

Ou, até mesmo por:

3')) O sentido do texto está todo nele.

O texto fomentaria respostas prontas, ou seja, há aí novamente o recorte de um memorável muito comum às escolas: a prática de leitura e interpretação de textos e as respostas se dariam como blocos prontos 
retirados do texto, isto é, a unidade do texto é composta desses blocos. A compreensão de texto desse alocutor-professor influencia em sua prática pedagógica. Por ele acreditar que o texto não propicia uma reflexão, ele não trabalha com este objeto simbólico com frequência.

A parte (2) do recorte 3 é enunciada a partir de um enunciador individual. Projeta-se como futuridade de sentidos uma possível articulação da prática pedagógica do alocutor-professor com o texto para que os objetivos da disciplina sejam alcançados, quais sejam, os de propiciar a reflexão e promover a capacidade analítica do aluno.

No próximo recorte de outro alocutor-professor de Biologia, também temos a definição de texto pelo seu caráter informacional:

R4: Como você define o que é um texto para sua disciplina? Bom, tudo o que é informativo, né, pra mim, é, informativo, é, poderia ser uma pesquisa, um artigo, então, assim, eu acredito que as definições de texto são várias, uma poesia é um texto então é bastante abrangente, no meu ver.

O recorte é dito a partir de um enunciador individual, já que prevalece a opinião própria do alocutor-professor. A palavra texto é reescriturada por totalização em tudo e é predicada por informativo. $\mathrm{O}$ acontecimento da enunciação reescreve texto por pesquisa, artigo e poesia. Essas reescriturações relacionam-se hiponimicamente com tudo, de modo que elas compartilham o caráter informacional do texto enunciado inicialmente. Assim, podemos propor a seguinte paráfrase:

4') Uma pesquisa, um artigo e uma poesia são textos porque são informativos.

Ao eleger o caráter informativo do texto como principal, o alocutor-professor descaracteriza os textos, silencia outras possibilidades e propósitos para sua leitura. O que se ressalta é apenas a leitura para aprender e, ainda, pode-se resumir essa leitura ao aprendizado do conteúdo ministrado pela disciplina. A pergunta que se fica é: há espaço para leituras outras na escola? No espaço escolar de enunciação sobre o texto, apenas seu caráter informativo deve prevalecer em todas as disciplinas? São questionamento que tentaremos abordar ao longo de nossas análises. 
Note-se que uma leitura para informar os alunos é construída pela própria Escola como fundamental. Os textos citados nas entrevistas são predominantemente informativos como artigos de revistas, jornais, periódicos especializados e literatura relacionada à área.

Quando outros textos não informativos são citados, o objetivo da leitura ainda é o resgate de um conteúdo ensinado, como é o caso do recorte abaixo, que é resposta à pergunta: Quais textos e de quais fontes você utiliza em sala de aula?

R5: Literatura própria. No caso alguns livros de evolução, ecologia alguma coisa bem específica voltada para essa área é o que eu uso, às vezes, não sei se vai enquadrar como texto, mas como meio de transmitir informação, às vezes, é alguma tirinha alguma coisa, é... nesse sentido também utilizo pra tentar propiciar alguma reflexão em cima. Tem algumas tirinhas, inclusive brasileiras, Armandinho, tem a americana, se eu não me engano, a Calvin e Haroldo. Então, tem algumas coisas que dá pra associar ao conteúdo de Biologia ou Ciências, no caso, né.

Esse recorte é enunciado a partir de um enunciador individual marcado por uma prática pedagógica bastante específica do alocutorprofessor de Biologia. No recorte, tirinha é definida como meio de transmitir informação para propiciar alguma reflexão. A tirinha é um texto (uma unidade de sentido) que, em suas condições mais comuns de produção em jornais e internet, caracteriza-se por linguagem verbal e não verbal e cujo objetivo é o entretenimento do leitor. No entanto, não há preocupação em saber se é texto ou não. Há uma dúvida por parte do alocutor-professor em enquadrar a tirinha como texto talvez pelo memorável do sentido de texto como conjunto de palavras que significa na enunciação dessa palavra. Ou seja, seria texto para esse alocutor-professor de Biologia apenas aquilo que se caracteriza como verbal e informativo. E o que importa de fato é saber se o meio que se utiliza nas aulas transmitirá a informação, o conteúdo da disciplina.

No próximo recorte, da disciplina de Sociologia, vemos a informação sendo reescriturada por ideias e estas na relação com um autor. 
R6: Como você define o que é um texto para sua disciplina? é, num primeiro momento ele é informativo e no segundo momento o texto ele passa, é, no caso da Sociologia, especificamente, ele passa as ideias do próprio sociólogo em relação a como ele entende a sociedade.

O alocutor-professor de Sociologia enuncia a partir de um enunciador coletivo, a partir do espaço de enunciação da Sociologia. $\mathrm{O}$ texto é definido enumerativamente. Primeiro, predicado pela palavra informativo, ele visa informar e, em seguida, passar as ideias de um sociólogo. Podemos parafrasear esta enumeração por: $O$ texto é informativo e passa as ideias de um sociólogo. Veja-se que informar e passar as ideias de um sociólogo recortam memoráveis diferentes. Um termo não é a reescrituração do outro. A palavra informativo recorta como memorável a informação do texto, seu conteúdo e passar as ideias de um sociólogo recorta como memorável primeiramente que esse conteúdo refere-se a um modo de pensar próprio de um sociólogo e, juntamente, que esse sociólogo é o autor do texto. Em resumo, a designação de texto desse alocutor-professor é aquilo que possui um conteúdo informativo de um autor.

No recorte da disciplina de História, temos uma ampliação de palavras que predicam texto, mas este ainda transmite/comunica uma informação.

R7: Como você define o que é um texto para sua disciplina? É, assim, a definição que os historiadores utilizam de texto é toda forma de comunicação escrita que tenha sentido, nexo, finalidade e tenha como, é... princípio básico comunicar um fato, um evento, uma opinião, uma expressão de sentimento.

O alocutor-professor de História enuncia sua definição de texto a partir de um enunciador coletivo. Ele insere sua definição em uma coletividade, um campo já estabelecido, o campo da História. Sua voz está diluída nesta coletividade. Ao inserir-se nesse campo, o alocutorprofessor procura uma autorização para seu dizer: uma sustentação. Os historiadores é uma argumentação apresentada pelo alocutor. Historiadores coloca o dizer no discurso científico da História. Projeta uma cientificidade para a argumentação do alocutor-professor. 
A palavra texto é reescriturada por definição expansiva em toda forma de comunicação escrita que tenha sentido, nexo, finalidade e tenha como princípio básico comunicar um fato, um evento, uma opinião, uma expressão de sentimento. Também podemos entender que a definição de texto aparece enumerativamente e, assim, pode ser parafraseada das seguintes formas:

7') texto é toda forma de comunicação escrita com sentido, nexo, finalidade.

7') O texto tem como princípio básico comunicar um fato, um evento, uma opinião.

7"',) O texto é uma expressão de sentimento.

Há, na paráfrase 7'), a articulação de palavras que predicam texto. Na paráfrase 7'), princípio básico predica o objetivo do texto, qual seja, comunicar, e pode ser entendido como uma reescrituração de finalidade. Na paráfrase 7'"'), a expressão de sentimento também pode ser entendida como um dos objetivos do texto, ou seja, o texto também tem por objetivo expressar um sentimento. Não se pode dizer que a definição de texto no recorte coloca apenas o caráter informacional do texto como principal, no entanto, o texto está predicado pela comunicação e, assim, uma compreensão de língua transparente e a-histórica em que os sentidos sempre podem ser apreendidos.

O próximo recorte é de um dos alocutores-professores de Física. Não há coincidência de sentidos entre os dois alocutores, portanto, colocamos um aqui e outro em outra seção. Iniciemos com o alocutorprofessor de Física 1:

R8: Como você define o que é um texto para sua disciplina? Física1: O texto, ele pode ter ... pode ser escrito ou pode ser através de charges, figura. É pra levar o aluno a interpretar uma figura ou até mesmo a ... um texto literário, um poema, tudo isso para trabalhar na Física, uma música, eu considero que seja um texto.

O recorte 8 traz uma definição bastante abrangente para o texto. Essa palavra é definida por uma enumeração que podemos apresentar 
por: $O$ texto pode ser escrito ou através de charges, figuras ou pode ser literário. No primeiro enunciado, o texto pode ser escrito, temos a palavra escrito predicando texto. Esse enunciado pode ser parafraseado por:

\section{8') o texto pode ser composto por linguagem verbal.}

No segundo item enumerativo, temos charges e figuras predicando texto. Esses são textos que podem ser compostos por linguagem verbal e não verbal e esses dois textos são apresentados em uma relação hiponímica com texto. E na última enumeração, a palavra literário aparece articulada por definição a texto e assim caracteriza um novo tipo de texto.

Esses três itens enumerativos: o texto escrito, o texto que pode ser através de charges e figuras e o texto literário recortam memoráveis diferentes para a palavra texto. No texto escrito, tem-se o memorável do texto composto apenas por linguagem verbal, em charges e figuras, tem-se o texto composto por linguagem verbal e não verbal. Ainda com esses dois memoráveis temos o sentido de textos que são não ficcionais. O texto literário recorta como memorável os textos que são da ordem do ficcional. Esses textos são trabalhados na aula de Física com o objetivo de interpretação. Recorta-se como memorável com essa palavra os exaustivos exercícios de interpretação de texto correntes das escolas e sabemos que esses exercícios, muitas vezes, trazem respostas prontas desde o livro didático.

\section{O texto como conjunto de palavras}

Reunimos nesta seção as disciplinas que compreendem o texto como conjunto de palavras, ideias, informações que podem ou não se ligarem a um autor. Esse conjunto rememora um sentido de língua matematizável, limitada por sentidos fixos. São essas disciplinas: Língua Inglesa, Física 2, Geografia e Filosofia.

Iniciamos com o recorte da disciplina de Língua Inglesa:

R9: Como você define o que é um texto para sua disciplina? Texto é um conjunto de palavras onde buscamos, muitas vezes, respostas para o que precisamos. 
Neste recorte, encontramos um sentido muito comum ao texto na Escola: como conjunto de palavras. Essa definição de texto exclui outras definições que o consideram como uma unidade de sentidos. De saída, coloca o texto apenas no domínio do verbal. O alocutárioprofessor fala a partir de um enunciador-universal. O nós a quem a enunciação faz referência não inclui apenas a coletividade de professores, mas abrange outras coletividades. O pronome onde predica para texto um sentido de lugar. Lugar onde se busca respostas. Enunciar que no texto buscamos respostas recorta como memorável um sentido de uma prática escolar muito comum relacionada ao texto: a leitura de um texto e um questionário que se segue a essa leitura. Essa prática escolar comum não coloca em relevo o texto, mas as respostas a ele. A designação do texto como um conjunto de palavras e como um lugar de respostas não mantém nenhuma relação com um sujeito que o produz. Texto também está nesse recorte como um objeto que se encerra em si mesmo.

Enunciar que o texto é conjunto de palavras recorta como memorável um sentido de produto ou objeto acabado e descaracteriza o processo histórico-social da enunciação linguística. Igualmente, a palavra conjunto traz consigo o sentido de reunião ou coleção finita de alguma coisa, no caso da enunciação em questão, palavras ou sentenças. Os conjuntos são típicos ao espaço de enunciação da Matemática e o enunciado texto é um conjunto de palavras temporaliza, nesta enunciação, estes dois sentidos, o da Matemática e o da linguagem. Ou, em outras palavras, este enunciado matematiza o dizer, no sentido de que as palavras correspondem-se aos números e podem ser reunidas em conjuntos denominados textos.

No próximo recorte, correspondente ao segundo alocutor-professor de Física 2, mantém-se o mesmo sentido para texto:

R10: Como você define o que é um texto para sua disciplina? Física 2: Para mim, seria um conjunto de informações, podendo ele ser uma informação, um fato acontecido, de fato, verdadeiro, podendo ser uma história, podendo ser algo inventado. Seria, para mim, isso.

Esse recorte é dito a partir de um enunciador-individual que predica para o texto apenas o caráter informativo. O texto é 
novamente predicado pela palavra conjunto, que, já o dissemos, recorta como memorável uma região delimitada. O texto pode ser a representação de um fato verdadeiro, acontecido, portanto uma informação e o texto pode ser a representação de algo inventado, portanto uma história ficcional. O pronome anafórico isso é a reescrituração de todo o enunciado anterior, totalizando as duas definições de texto. Ou seja, temos que a enunciação liga informação como um predicado para o fato acontecido verdadeiro e a história ficcional.

Vejamos a designação de texto para a disciplina de Geografia:

R11: Como você define o que é um texto para sua disciplina? texto, para mim, é um conjunto de ideias, né, explícitas ali, em sequência com um objetivo determinado.

$\mathrm{O}$ alocutor-professor apresenta sua definição de texto a partir de um enunciador individual marcado pelo emprego de para mim, ou seja, uma opinião do que este alocutor entende por texto. A definição comum de texto como conjunto de palavras desliza para conjunto de ideias, na definição do alocutor-professor. Há um sentido de palavras que permite esse deslizamento para ideias de modo que a seguinte paráfrase seja possível: palavras são ideias ou palavras representam ideias. O texto, portanto, representa as ideias de um suposto autor. Essas ideias devem estar explícitas na superfície textual. O texto é entendido como um produto, um conjunto finito de palavras, ou, igualmente, o texto é produto da intencionalidade de um autor. O texto é visto pela sua linearidade ou sequência de ideias. A locução: em sequência, juntamente com a palavra explícita, determinam conjunto de ideias e este último, juntamente com objetivo, determinam texto.

O texto, portanto, deve apresentar um conjunto de ideias explícitas em sequência com um determinado objetivo. Ao falar de conjunto de ideias, vê-se que o texto é definido novamente na relação com a mente, como na designação da disciplina de História, e não com o mundo, com as informações.

No próximo recorte, da disciplina de Filosofia, mantém-se o sentido de um texto com uma progressão de assunto sequencial (um conteúdo disciplinar). Há o acréscimo da menção do texto na relação com um autor. 
Consideremos para a análise o seguinte recorte:

R12: Como você define o que é um texto para sua disciplina? (1) Pois é, o texto pode ser desde um parágrafo, onde tem uma ideia clássica, né? Por exemplo, "Penso, logo existo" é um texto. E pode ser também duas, três ou mais páginas onde o autor aborde algum assunto que... de interesse, então... exemplo: nós estamos trabalhando, ultimamente, o fenômeno da felicidade à luz da Filosofia. E a gente lê textos assim onde cada filósofo aborda a felicidade à sua maneira e, portanto, texto é qualquer ideia que possa ser expressa literalmente... é... com apenas uma linha ou uma folha ou duas ou até mais, né? Desde que fique fixo num ponto, ou seja, desenvolva, discorra sobre uma questão, um objeto. Isso, para mim, é um texto.

Neste recorte, a definição de texto pode ser parafraseada por:

12') texto é a expressão coerente e por escrito da ideia de um autor a respeito de um assunto cuja extensão pode ser desde uma frase a várias páginas.

O enunciado (1) é dito pelo alocutor-professor de Filosofia a partir do enunciador individual, pois expressa sua opinião a respeito da definição de texto. Note-se que o alocutor enuncia que o texto pode ser um parágrafo, mas dá exemplo de uma citação famosa do filósofo René Descartes: "Penso, logo existo". Portanto, um texto também pode ser uma frase ou citação, tanto que podemos propor a seguinte paráfrase:

12") a citação "Penso, logo existo" é um texto.

O alocutor não cita o autor dessa citação, mas deixa explícito no próximo enunciado que o texto deve trazer as ideias de um autor, portanto autor determina os sentidos de texto. Cabe ressaltar que uma citação como a acima não é apenas uma frase, mas encerra uma ideia de um autor. De acordo com o recorte, não é qualquer frase que pode ser um texto, mas uma frase que encerre uma ideia. 
A primeira ocorrência da palavra texto aparece articulada com o verbo lê e em uma denominação geral. Nessa articulação, a palavra Textos pode ser parafraseada por:

\section{2,') qualquer texto disponivel.}

Neste mesmo enunciado, a palavra filósofo pode ser entendida como a reescrituração por substituição de autor e felicidade a reescrituração de assunto. Em seguida, há o articulador portanto que articula para uma conclusão, sendo essa a que se expressa na seguinte reescrituração por expansão da palavra texto: qualquer ideia que possa ser expressa literalmente. Temos ainda, no último enunciado do recorte, o pronome anafórico isso que é a reescrituração por totalização de todo o recorte.

\section{O texto na relação com o contexto}

Neste grupo, inserimos as disciplinas cujas designações de texto reportam-no ao contexto, ou seja, a um fora do texto. Contexto, aqui, está em relação parafrástica com pano de fundo. Essas disciplinas compreendem que o texto refere-se a algo fora dele, uma situação no mundo real. São essas disciplinas Arte, Química e Matemática.

Para a disciplina de Arte, consideremos para a análise o seguinte recorte:

R13: Como você define o que é um texto para sua disciplina? Tem vários, né, tem o texto contextualizado. Um texto que é um texto, né, mas geralmente, o texto tem que vir em forma de contextualização porque pro aluno fica mais fácil ele tá trabalhando vários ângulos dentro da obra de arte.

De saída, atentemos para a assimetria na resposta à pergunta. Esta interroga sobre a definição de texto e a resposta traz: Tem vários, né. E não várias, que traria várias definições. A definição talvez para este professor-alocutor é uma só, mas há uma variedade de textos, vários textos. Neste recorte, não há uma definição própria de texto, o acontecimento da enunciação recorta dois memoráveis para o texto. $\mathrm{O}$ enunciado tem vários é reescriturado por enumeração em: a) texto contextualizado e b) texto que é um texto. Essas duas reescriturações 
definem vários. No enunciado a), contextualizado articula-se por dependência a texto e recorta este memorável para o texto: o texto tem um contexto. A contextualização refere-se ao trabalho com o texto, ou seja, um ângulo de trabalho com o texto para que o aluno possa compreender a obra de arte.

O texto determinado por um contexto que lhe é exterior corresponde a um sentido bastante pragmático de texto. Não há um lugar para o sujeito neste sentido.

No enunciado b), há um pré-construído sobre o texto que funciona na evidência de seu sentido: texto que é um texto. Não se trata de uma tautologia. Veja-se que, no espaço escolar de enunciação sobre o texto, parece que o definir é desnecessário. Tem-se um texto que é ele mesmo e assim basta para sua definição. Neste segundo memorável, temos o texto como um objeto que se encerra em si mesmo.

Veja-se que o alocutor-professor coloca uma ênfase maior no texto contextualizado. $\mathrm{O}$ texto contextualizado, segundo este alocutorprofessor, facilitaria o aprendizado do aluno. O aluno então é este que precisa ter seu aprendizado facilitado. Um sujeito sempre em via de aprender algo.

O contexto também está presente na disciplina de Química:

R14: Como você define o que é um texto para sua disciplina? (1) texto não tem ... eu não sei uma definição para texto. (2) Que texto depende do conte... eu vou falar feio o texto depende do contexto, pode ser uma matéria jornalística pode ser até uma piada pode ser texto, né, uma informação passada de forma escrita, né.

No enunciado (1), o alocutor-professor de Química, a partir de um lugar de dizer marcado pela individualidade, diz não saber a definição de texto. Esse enunciado marca um distanciamento entre esse objeto simbólico - o texto - e o trabalho pedagógico desse professor. Uma definição de texto não lhe caberia como professor de Química. Isso fica evidente no enunciado eu vou falar feio, que marca uma distância entre uma necessidade de saber uma definição de texto e sua prática pedagógica.

Note-se que a palavra texto é reescriturada por repetição cinco vezes no recorte. Em duas delas, a palavra insere-se em enunciados 
em que há hesitação na sua definição: o texto não tem... e que texto depende do conte... E então, o recorte traz informações que nos permite construir uma designação para texto. No enunciado (2), texto é predicado pela palavra contexto e, ao final do recorte, texto é reescriturado por definição em informação passada de forma escrita.

$\mathrm{O}$ recorte ainda traz matéria jornalística e piada em relação hiponímica com texto. Essa palavra é reescriturada por elipse em dois enunciados:

14') [Texto] pode ser uma matéria jornalística.

14',) [Texto] pode ser até uma piada.

Como funciona enunciativamente o até neste último enunciado? A enunciação de piada recorta como memorável uma certa informalidade para este texto. Dentro do espaço de enunciação escolar, as piadas não são muito comuns como objetos de ensino. Uma piada também não possui um caráter informativo, mas até uma piada precisa de um contexto para ser entendida.

Vejamos agora como o fora do texto está para a disciplina de Matemática. Consideremos para a análise o seguinte recorte:

R15: Como você define o que é um texto para sua disciplina? Texto... ah, uma apresentação de alguma situação, uma expressão de de de de alguma... a descrição de alguma situação, a descrição de algum problema. Isso no caso da Matemática.

O alocutor-professor de Matemática, a partir de um enunciador individual, define a palavra texto enumerativamente. Essa enumeração pode ser parafraseada por:

15') texto é a uma apresentação de alguma situação.

15 ') Texto é uma expressão de alguma situação.

15 ,') Texto é a descrição de alguma situação.

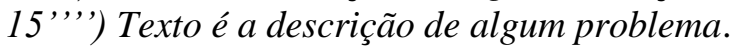

Veja-se que podemos retirar das paráfrases três verbos: apresentar, expressar e descrever. Eles são empregados para predicar sobre os 
objetivos de um texto. Esses verbos recortam como memorável as tipologias textuais, já tratadas anteriormente. A palavra situação é reescriturada duas vezes no recorte, uma por elipse e outra por repetição. As palavras expressão e problema são nomes comuns ao espaço de enunciação da Matemática. Esses nomes, geralmente, descrevem os enunciados de resolução de exercícios matemáticos. $\mathrm{O}$ texto, então, seria essa apresentação em linguagem verbal desses enunciados.

\section{Considerações finais}

As palavras significam pela história de suas enunciações. A língua, definida como "uma dispersão de regularidades linguísticas constituídas sócio-historicamente" (GUIMARÃES, p. 76, 1989), só funciona afetada pela história. O acontecimento da enunciação é atravessado pelo interdiscurso, a memória de sentidos das palavras. Estas recortam diferentes memoráveis a partir dos enunciados que constituem.

Ao longo das análises deste trabalho, pode-se perceber que a palavra texto recorta diferentes memoráveis a partir da posição de alocutor que a enuncia. Diferentes foram os professores entrevistados, diferentes são as formações discursivas que os afetam. Os sentidos nunca são únicos, são divididos, múltiplos, políticos, incompletos.

A palavra texto, enunciada no espaço escolar, encontra-se ainda fortemente afetada pelo sentido de uma língua voltada à comunicação e informação. Ela também ainda está voltada à comum e difundida prática de interpretação de textos. Nesta prática, geralmente, distribuise um texto verbal escrito qualquer sem que se trabalhe sua estrutura e constituição, apenas o seu conteúdo, e os alunos, após a leitura, respondem a um questionário que obedece rigidamente à estrutura começo, meio e fim do texto, sendo cada pergunta sobre um parágrafo.

Outras palavras se regularizam ao predicar texto, como contexto, mensagem, conjunto de palavras, conjunto de ideias. Essas palavras estão ligadas a um sentido bastante pragmático de texto. Segundo Orlandi (2014, p. 68): “o pragmatismo acaba por obscurecer o lugar da língua, ao tratar do contexto, dos atos da linguagem, das implicaturas ou funções da linguagem". O texto contextualizado visa a facilitar sua interpretação para os alunos (como se vê na disciplina de 
Arte) ou permitir uma interdisciplinaridade com as outras disciplinas (como se vê em Matemática). Mas, interpreta-se o texto desde que o atravesse para resgatar um conteúdo (disciplinar ou não) do outro lado.

Sendo o texto um meio para uma função comunicativa, seu leitor, no caso, o aluno, estaria na linearidade temporal de sua produção. Ele simplesmente resgataria no texto uma informação, uma mensagem, uma ideia. Mas a informação deve ser transformada em conhecimento. O lugar que se coloca para esse aluno é o lugar daquele que deve aprender sempre e produzir textos adequados, corretos, coerentes.

\section{Referências}

GALLO, S. Texto: como apre(e)nder essa matéria? 1994. Tese (Doutorado em Linguística) - Instituto de Estudos da Linguagem, Universidade Estadual de Campinas, Campinas, 1994.

GUIMARÃES, E. R. J. Enunciação e História. In: GUIMARÃES, E. (org.). História e sentido na linguagem. Campinas: Pontes, 1989, p.71-79.

GUIMARÃES, E. R. J.; ORLANDI, E. Unidade e dispersão: uma questão do texto e do sujeito. In: ORLANDI, E. (Org). Discurso e Leitura. São Paulo: Cortez, 1988.

GUIMARÃES, E. R. J. Os sentidos de cidadão no Império e na República no Brasil. Signo e Seña, Filo/UBA, n. 1, p. 103-114, 1992.

GUIMARÃES, E. R. J. Texto e enunciação. Organon, Rio Grande do Sul: UFRGS, v. 9, n. 23, p. 65-69, 1995.

GUIMARÃES, E. R. J. Política de Línguas na América Latina. Relatos, Campinas, n.7, p. 5-11, 2001.

GUimarãeS, E. R. J. Semântica do Acontecimento. Campinas: Pontes, 2002.

GUIMARÃES, E. R. J. A enumeração funcionamento enunciativo e sentido. Caderno de Estudos Linguísticos, Campinas, 51(1), p. 4968, jan/jun., 2009.

GUIMARÃES, E. R. J. O sentido de história em dois estruturalistas brasileiros. Língua e Instrumentos Linguísticos, Campinas, n. 25, p. 9-18, 2010.

GUIMARÃES, E. R. J. Análise de texto. Procedimentos, análises, ensino. Campinas: RG Editora, 2011. 
GUIMARÃES, E. R. J. Ler um Texto: uma Perspectiva Enunciativa. Revista da ABRALIN, [s.l.], v. XII, 2, p. 189-205, 2013.

GUIMARÃES, E. R. J. Semântica: enunciação e sentido. Campinas, SP: Pontes, 2019.

LAGAZZI, S. M. A sala de aula e o alhures: circulando pela linguagem entre práticas e teorias. Letras, Santa Maria, UFSM, v. 27, p. 67-72, 2003.

ORLANDI, E. P. Ciência da Linguagem e Política: anotações ao pé das letras. Campinas: Pontes, 2014.

PÊCHEUX, M. Análise automática do discurso - 1969. In: GADET, F.; HAK, T. (Orgs.). Por uma análise automática do discurso: Uma introdução à obra de Michel Pêcheux. 5. ed. Campinas, SP: Unicamp, 2014. p. 61-162.

PFEIFFER, C. C. Bem dizer e retórica: um lugar para o sujeito. 2000. Tese (Doutorado em Linguística) - Instituto de Estudos da Linguagem, Universidade Estadual de Campinas, 2000.

PFEIFFER, C. C. Políticas Públicas: Educação e Linguagem. Caderno de Estudos Linguísticos, Campinas, Unicamp, v. 53 (2), p. 149-155, Jul./Dez, 2011.

SCHEREIBER DA SILVA, S.; STEIGENBERGER, F. F.; MACHADO, J. C. Fronteira entre análise de discurso e semântica histórica da enunciação: abordagens teóricas. Revista de Estudos da Linguagem, Belo Horizonte, v. 19, n. 2, p. 51-79, jul/dez., 2011. ZOPPI FONTANA, M. A Arte do Detalhe. Web Revista Discursividade, Estudos Linguísticos, Campo Grande, n. 9, 2012.

\section{Notas}

* Doutor em Linguística pela UNICAMP. Docente da Universidade do Vale do Sapucaí (UNIVÁS).

1 Para Guimarães (2002): A designação é a significação de um nome, mas não enquanto algo abstrato e referencial, mas uma relação que se dá na língua, ou seja, uma relação simbólica, histórica e exposta ao real. É o sentido de um nome estabelecendo a relação desse nome com as coisas tomadas como existentes.

2 Três esclarecimentos: a) Não foi contemplada a disciplina de Educação Física porque, nesta escola, ela está fortemente ligada ao esporte. Portanto, não há a exigência de uma matéria a ser ensinada, trabalhos ou avaliações escritas. No entanto, sabemos que as práticas linguageiras durante as aulas de Educação Física constituem os sujeitos nelas envolvidos. Não há como estar fora da linguagem. Mas, não é 
objetivo deste trabalho estudar essas práticas. b) dois professores de Física e dois de Biologia foram entrevistados. Esses professores dão aulas em outras escolas e completam o número de aulas obrigatórias semanais na escola de nossa pesquisa. c) As disciplinas de Língua Portuguesa e Literatura embora sejam em horários diferentes, são ministradas pela mesma professora.

3 Denominação posteriormente mudada para alocutor-x em Guimarães (2018). Empregaremos essa nova denominação nas análises.

4 A tensão entre paráfrase e polissemia é constituinte de qualquer discurso. A paráfrase refere-se ao mesmo dizer sedimentado e a polissemia refere-se ao diferente, ao rompimento, "essa força na linguagem que desloca o mesmo, o garantido, o sedimentado" (ORLANDI, 1988/2011, p. 27).

5 Traremos os recortes numerados e centralizados para uma melhor visualização. 